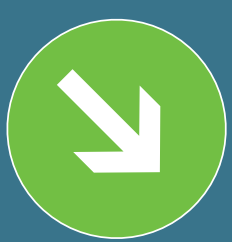

Ключевые слова:

твердый сплав,

монолитные фрезы, износ

\section{СРАВНИТЕЛЬНЫЕ ИСПЫТАНИЯ КОНЦЕВЫХ ТВЕРДОСПЛАВНЫХ} ФРЕ3

\author{
Виктор АНДРЕЕВ, Сергей МОЛОДЫК, Сергей МИНАЙЛОВ, \\ Ярослав МИНЕНКО, МИХаил НАДОЛЬСКИЙ, ЕвГеНИЙ НЕГИНСКИЙ
}

Приведены результаты испытаний концевых твердосплавных фрез, изготовленных из твердосплавных стержней различных фирм - изготовителей.

В АО «ВНИИИНСТРУМЕНТ» были проведены сравнительные испытания по выявлению режущих свойств концевых твердосплавных фрез, изготовленных в ООО «Специнструмент», получившем подтверждение Минпромторга о производстве промышленной продукции на территории Российской Федерации с использованием твердосплавных стержней $[1,2]$ фирмы Gühring из твердого сплава DK460С и осваиваемой продукции АО «Победит» из твердого сплава BК10XOM.

Испытания проводились в соответствии с методи кой, разработанной в АО «ВНИИИНСТРУМЕНТ» совместно с ОOО «Специнструмент».

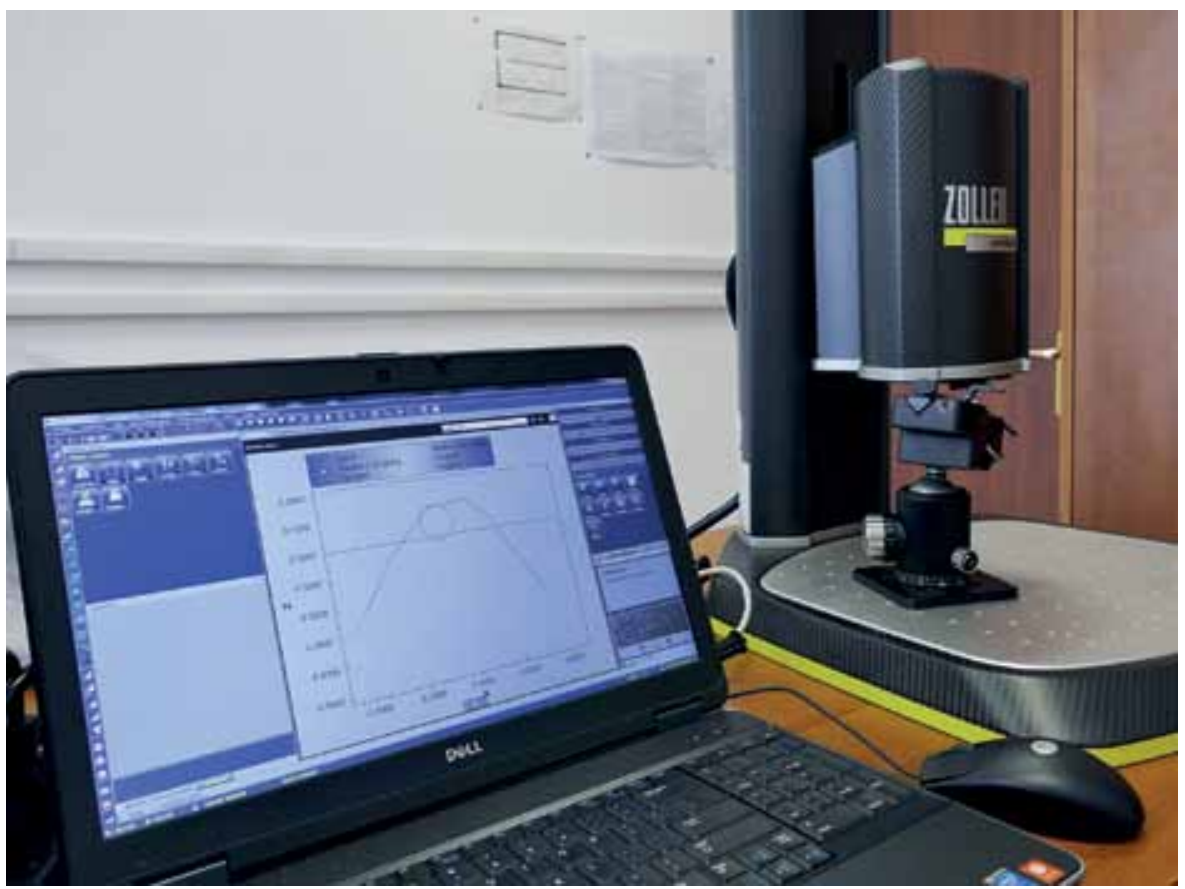

Puc. 1. Прибор «pomSkpGo» Zoller GmbH

Испытания фрез проводились на многоцелевом обрабатывающем центре $528 \mathrm{~S}$, разработанном совместно компаниями АО «ВНИИИНСТРУМЕНТ» и Willemin-Macodel.

В качестве обрабатываемого материала использовались заготовки из аустенитной стали $12 \mathrm{X} 18 \mathrm{H} 10 \mathrm{~T}$ размером $104 \times 93 \times 140$ мм с твердостью $175 . . .178$ НВ.

Испытывались концевые фрезы диаметром 10 мм с числом зубьев $z=4$, углом наклона винтовой канавки $\omega=37^{\circ}$, передним углом режущего клина $\gamma_{N}=2^{\circ}$, задним углом $\alpha_{N}=15^{\circ}(\mathrm{M}-10-22-10-72 \mathrm{~T} 4-\mathrm{U})$; $\mathrm{c} z=3, \omega=30^{\circ}, \gamma_{N}=3^{\circ}, \alpha_{N}=15^{\circ}(\mathrm{M}-10-22-10-72 \mathrm{~T} 3-\mathrm{U})$; c $z=4, \omega=37^{\circ}, \gamma_{N}=2^{\circ}, \alpha_{N}=12^{\circ}\left(10-10-72-22-\mathrm{R} 0,5^{-}\right.$ Z4-S-S.I).

Для крепления фрез использовался фрезерный патрон цанговый HSK - 63AXER $32 \times 100$.

Для контроля состояния режущего клина зуба фрезы использовался прибор «pomSkpGo» Zoller $\mathrm{GmbH}$ (рис. 1).

Для измерения износа зубьев использовался микроскоп БМИ-1. Для измерения твердости обрабатываемых заготовок использовался прибор ТШ-2. 
Таблица 1. Результаты испытаний режущих свойств концевых твердосплавных фрез

\begin{tabular}{|c|c|c|c|c|}
\hline Номенклатура фрез & $\begin{array}{c}\text { Износ, } \\
h_{3} \mathrm{Mм}\end{array}$ & $\begin{array}{c}\text { Время резания, } \\
T \text { мин }\end{array}$ & $\begin{array}{c}\text { Износ*, } \\
h_{3} \text { мм }\end{array}$ & $\begin{array}{c}\text { Время резания } \\
T \text { мин }\end{array}$ \\
\hline$M-10-22-10-72 T 4-U$ & $\begin{array}{l}0,13 \\
0,30\end{array}$ & $\begin{array}{l}22,5 \\
37,5\end{array}$ & $\begin{array}{l}0,13 \\
0,38\end{array}$ & $\begin{array}{l}22,5 \\
30,0\end{array}$ \\
\hline$M-10-22-10-72 T 3-U$ & $\begin{array}{l}0,14 \\
0,25 \\
0,90\end{array}$ & $\begin{array}{l}30 \\
40 \\
43\end{array}$ & $\begin{array}{c}0,156 \\
0,45\end{array}$ & $\begin{array}{l}20,0 \\
24,6\end{array}$ \\
\hline \multirow[t]{2}{*}{ 10-10-72-22-R0,5-Z4-S-S.I } & $\begin{array}{l}0,12 \\
0,20 \\
0,60\end{array}$ & $\begin{array}{l}15,0 \\
22,5 \\
25,0\end{array}$ & $\begin{array}{l}0,15 \\
0,25 \\
0,90\end{array}$ & $\begin{array}{c}7,5 \\
10,0 \\
14,0\end{array}$ \\
\hline & $\begin{array}{l}0,12 \\
0,32\end{array}$ & $\begin{array}{l}15,0 \\
22,5\end{array}$ & & \\
\hline
\end{tabular}

* Фрезы, изготовленные из стержней АО «Победит»
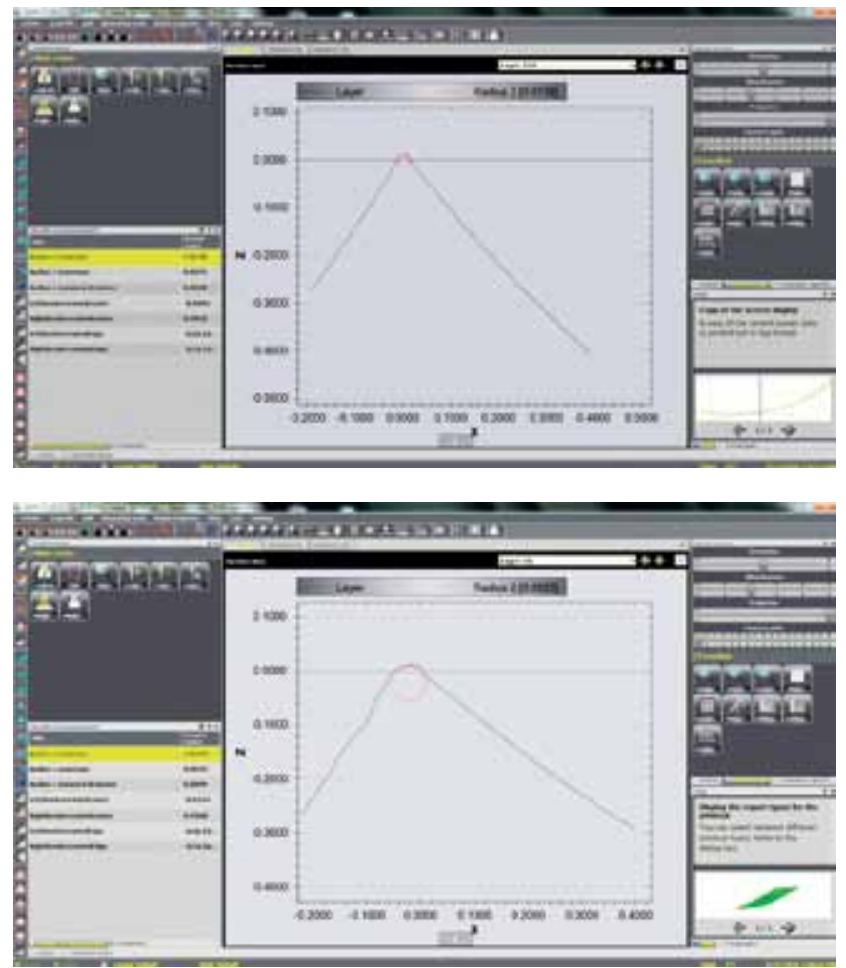

Puc. 2. Увеличение радиуса округления режущих кромок при обработке стали $12 \mathrm{X} 18 \mathrm{H} 10 \mathrm{~T}$

\section{УСЛОВИЯ ПРОВЕДЕНИЯ ИСПЫТАНИЙ}

Скорость резания - 84,7 м/мин, подача на зуб 0,06 мм, глубина резания - 2 мм, ширина резания 5 мм.

Критерий затупления зубьев фрез - износ по задней поверхности режущего клина равный 0,3 мм, при этом износ определяется как среднее арифметическое значений износа всех зубьев фрезы. Допустимая величина износа $-h_{3}=0,3$ мм, выбираемая в качестве критерия затупления, обусловлена тем, что при увеличении износа выше указанного имеет место катастрофический износ.

Использовалось обильное охлаждение - $10 \%$-ный раствор ЭГТ в воде.

Фрезерование попутное.

\section{РЕЗУЛЬТАТЫ ИСПЫТАНИЙ}

Результаты испытаний представлены в табл. 1.

Анализ полученных данных показывает, что стойкость фрез М-10-22-10-72T4-U, изготовленных из твердосплавных стержней фирмы Gühring, при износе зубьев по задней поверхности, равном 0,3 мм, составила 37 мин, изготовленных из стержней АО «Победит» - 27,5 мин.

Стойкость фрез M-10-22-10-72Т3-U, изготовленных из стержней фирмы Gühring, составляла 41 мин, а фрез, изготовленных из стержней АО «Победит» $-22,5$ мин.

Стойкость фрез 10-10-72-22-R0,5-Z4-S-S.I, изготовленных из стержней фирмы Gühring, составляла в среднем 22 мин, а фрез, изготовленных из стержней $\mathrm{AO}$ «Победит» -12 мин.

Учитывая то, что каждый тип фрез изготавливался из двух сравниваемых твердосплавных стержней и испытывался в аналогичных условиях, показатели стойкости различных типов фрез можно усреднить, то есть стойкость фрез, изготовленных из стержней фирмы Gühring превышала стойкость фрез, изготовленных из стержней АО «Победит» в 1,6 раза.

При обработке стали 12X18Н10T радиус округления режущих кромок увеличивался с 10 до 40 мкм (рис. 2), причем, вследствие создания более неблагоприятных условий в зоне стружкообразования, это увеличение сопровождалось микросколами режущих кромок, которые впоследствии переходили в макросколы режущих кромок фрез (рис. 3).

Следует отметить, что интенсивность увеличения радиуса округления режущих кромок возможно уменьшить путем их «галтовки» вследствие достижения более равномерно упрочненного состояния режущих кромок по их длине. При этом оптимально заданная величина радиуса округления 


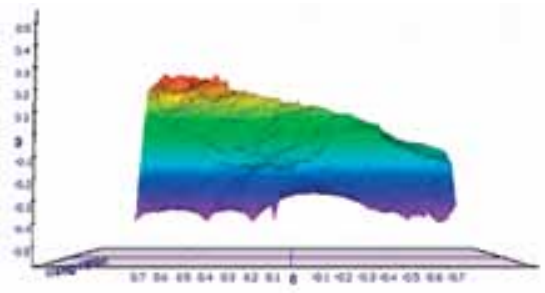

Puc. 3. Макросколы режущих кромок фрез

режущих кромок будет зависеть от обрабатываемого материала и режимов резания.

\section{ЛИТЕРАТУРА}

1. Андреев В. Н., Балков В. П., Боровский Г. В., Молодык С.У., Радциг Н. М. Современные направления улучшения твердых сплавов при производстве стержней для режущего инструмента // Вестник МГТУ «СТАНКИН». 2014. № 4 (31). 5 c.

2. Андреев В.Н., Боровский Г. В., Молодык С. У., Фальковский А. В. Совершенствование твердого сплава режущего инструмента // Технология машиностроения. 2012. № 2. 5 с.
АНДРЕЕВ Виктор Николаевич кандидат технических наук, заведующий лабораторией АО «ВНИИИНСТРУМЕНТ»

молодык Сергей Ульрихович кандидат технических наук, заведующий отделом АО «ВНИИИНСТРУМЕНТ»
МИНАЙЛОВ Сергей Владимирович начальник планово-технического отдела 000 «Специнструмент»

\section{МИНЕНКО Ярослав Владимирович - старший инженер-программист 000 «Специнструмент»}

\section{НАДОЛЬСКИЙ Михаил Александрович - научный сотрудник отдела АО «ВНИИИНСТРУМЕНТ»}

НЕгИнСКИй Евгений Афанасьевич заместитель генерального директора по инновационным проектам АО «ВНИИИНСТРУМЕНТ»

\section{НОВЫЕ КНИГИ ИЗДАТЕЛЬСТВА «ТЕХНОСФЕРА»}

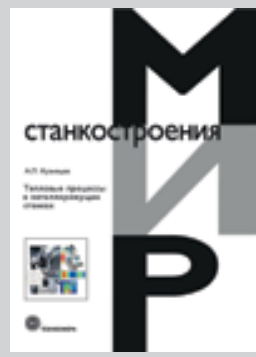

Цена 1090 руб.

\section{ТЕПЛОВЫЕ ПРОЦЕССЫ} В МЕТАЛЛОРЕЖУЩИХ СТАНКАХ
M.: TЕХHOСФЕРА,

2019. $-488 \mathrm{c}$.

ISBN 978-5-94836-477-3

\section{Кузнецов А.П.}

В книге рассматриваются методы оценки теплового режима металлорежущих станков и их наиболее теплонапряженных деталей и узлов. Приведен механизм формирования и теплофизического анализа теплового режима деталей и узлов металлорежущих станков, дана их теплофизическая классификация и описываются типовые тепловые модели. Приводятся аналитические зависимости для оценки стационарного и нестационарного теплового режимов деталей и узлов станков.

Приведена классификация методов воздействия на тепловой режим станков, описаны способы снижения, коррекции, компенсации и управления тепловым режимом металлорежущих станков.

Предлагаемая монография может быть полезна студентам, аспирантам, а также инженерам и специалистам, занимающимся вопросами повышения точности при проектировании, производстве и эксплуатации металлорежущих станков. 